\title{
A heranÇa de Leibniz na COMPREensão de lógica de Christian WOLFF
}

\author{
[LEIBNIZ'S HERITAGE IN UNDERSTANDING THE Christian WolfF's LOGIC]
}

Resumo: A tentativa de compreender a árvore genealógica da lógica geral, especialmente nos séculos XVII e XVIII e, particularmente, nos ambientes acadêmicos europeus, nos levou a uma investigação acerca da compreensão de lógica geral que encontramos em Christian Wolff. O estudo deste, por sua vez, nos mostrou que são duas as tradições que chegam à sua influência: a tradição da lógica das ideias, representada por John Locke e pelos Messieurs da Lógica de Port-Royal e a tradição escolástica, representada, notadamente, por Gottfried Wilhelm Leibniz. Neste texto, nos ocuparemos de retraçar, em linhas gerais, essa dupla influência com o objetivo de destacarmos aquilo que acreditamos ser a herança leibniziana da compreensão de lógica geral em Christian Wolff.

PALAVRAS-CHAVE: história da lógica; silogismo; Wolf; Leibniz
Mitieli Seixas da Silva* Universidade Federal de Santa Maria, Brasil
ABstract: The essay to understand the genealogic tree of the general logic, especially in the XVII and XVIII Century and, particularly, in the European Academy, leads us to a research on the comprehension of this discipline in Christian Wolff's philosophy. That study, in its turn, shows us that Wolff's influences are both the "Logic of Ideas" represented by the Messieurs of Port-Royal and John Locke, and the scholastic tradition represented, notably, by Leibniz. In this paper, we will retrace this double influence with the aim of accentuate the Leibnizian heritage in the comprehension of the general logic by Christian Wolff.

KEYWORDS: history of logic; syllogism; Wolff; Leibniz

\section{INTRODUÇÃO}

abemos que na Introdução da Lógica de Jäsche (as anotações das aulas de Kant compiladas por Jäsche e autorizadas por Kant para publicação), há algo parecido com um elogio à lógica de Christian Wolff: "é a melhor que se tem" (KANT, 2003, Ak. 21, p. 38). Sabemos também que o texto de Georg Friedrich Meier, Auszug aus der Verunftlehre, o qual servia para suas próprias aulas, seria um comentário do texto de Christian Wolff via o trabalho de Baumgarten. Ocorre que o próprio texto de Meier é o resultado do encontro de uma série de influências concomitantes dos manuais de lógica disponíveis na primeira metade do séc. XVIII. Por um lado, é notável a grande influência que a conhecida Lógica de Port-Royal

* Doutorado em Filosofia. Professora Adjunta do Curso de Filosofia da Universidade Federal de Santa Maria, UFSM. mailto: mitieli@yahoo.com.br 
exerce no mundo erudito europeu ainda no séc. XVIII, bem como a ampla recepção do Ensaio sobre o entendimento humano de John Locke. Por outro lado, tem-se, especialmente nas universidades alemãs, a continuação, na primeira metade desse mesmo século, da tradição escolástica representada pela filosofia de Christian Wolff (SALTIÉL, 2012, p. 14).

A tentativa de compreender a árvore genealógica da lógica geral, especialmente nos séculos XVII e XVIII e, particularmente, nos ambientes acadêmicos europeus, nos levou a uma investigação acerca da compreensão de lógica geral que encontramos em Christian Wolff. O estudo deste, por sua vez, nos mostrou que são duas as tradições que chegam à sua influência: a tradição da lógica das ideias, representada por John Locke e pelos Messieurs da Lógica de Port-Royal e a tradição escolástica, representada, notadamente, por Leibniz. Neste texto, nos ocuparemos de retraçar, em linhas gerais, essa dupla influência, para, em um segundo momento, destacarmos aquilo que acreditamos ser a herança leibniziana da compreensão de lógica geral em Christian Wolff.

\section{Christian WolfF, John Locke E A lógica COMo "ARTE de PENSAR"}

A obra de Christian Wolff que ficou conhecida como Lógica Alemã (1712) possui, na realidade, o comprido nome de Vernünftige Gedanken von den Kräften des menschlichen Verstandes und ihrem richtigen Gebrauch in der Erkenntnis der Wahrheit (Pensamentos racionais sobre os poderes do entendimento humano e seu uso correto no conhecimento da verdade). No Primeiro Prefácio dessa obra, encontramos um elogio da parte de Wolff aos poderes do entendimento humano. Essa referência entusiasmada aos poderes intelectuais do homem, como se sabe, será uma característica marcante do Iluminismo, o que justifica a identificação de Chistian Wolff como um dos precursores (senão o precursor) desse movimento na Alemanha (CAPOZZI; RONCAGLIA, 2009, p.126) $)^{2}$. O elogio às capacidades que podem conduzir ao conhecimento é seguido tendo em vista o objetivo declarado de se buscar a verdade - da justificação da lógica ora apresentada como sendo o resultado de uma investigação sobre essas capacidades:

O que notei na exposição de escritos matemáticos e na variada reflexão própria do uso das forças do entendimento humano, disso quis redigir da maneira mais fácil aquilo que é necessário saber em primeiro lugar em regras curtas. (WOLFF, 1736, a5-6, tradução própria) $)^{3}$.

A mesma compreensão do tipo de investigação que é a lógica aparece no § 10 do Discurso Preliminar à Lógica Alemã, onde Wolff escreve:

Quando observamos a nós mesmos, convencemo-nos de que há em nós uma faculdade de pensar o que é possível, a qual costumamos chamar de entendimento. Contudo não é evidente a todos o quanto se estende essa faculdade, e como se deve fazer uso da mesma, tanto através de reflexão própria para conhecer a verdade que nos é oculta, quanto para ajuizar de maneira razoável a verdade colocada à luz por outros. Por isso, para sabermos se somos ou não hábeis para a filosofia, esta deve ser nossa primeira tarefa: aprender a conhecer as forças do entendimento humano e seu uso correto no conhecimento da verdade. A parte da filosofia na qual isso é mostrado se chama lógica, ou arte da razão, ou ainda doutrina da razão. (WOLFF, 1744, p. 5-6, tradução própria) 
Duas observações merecem nossa atenção. Em primeiro lugar, de acordo com as citações acima, a lógica parece ser definida por Wolff como uma arte da razão (ou do entendimento), cuja "primeira ocupação" deve ser investigar as forças do entendimento humano em seu uso correto no conhecimento da verdade. No ambiente intelectual temporalmente anterior a Wolff, a ideia da lógica como arte de pensar consiste, antes de tudo, justamente na ênfase sobre a investigação das faculdades cognitivas, daquilo que ficou conhecido na literatura como o caminho ou lógica das ideias (SEIXAS DA SILVA, 2016, cap. 3.1.1).

Em segundo lugar, é interessante notar que o mesmo movimento (a saber, passar do elogio do entendimento à necessidade de conhecer até onde esses poderes se estendem e como se deve fazer uso do mesmo para se encontrar a verdade) é também encontrado na Introdução ao Primeiro Capítulo do Livro I do Ensaio do entendimento humano de John Locke. Ali vemos, embora em uma linguagem mais comedida, linhas bastante semelhantes àquelas de Christian Wolff:

Uma vez que é o entendimento aquilo que coloca o homem acima do resto dos seres sensíveis, e dá a ele toda a vantagem e o domínio que ele tem sobre os outros, esse certamente é um assunto valoroso de investigação, mesmo um dos mais nobres. [...] Este, portanto, é o meu propósito de investigar a originalidade, certeza e extensão do conhecimento humano; junto a isso, os fundamentos e os graus de crença, opinião e assentimento. (LOCKE, 1894, Livro I. I, 1, p. 43, tradução própria)

Assim, parece inegável a influência exercida pelo Ensaio (e pela tradição que essa obra representa) na constituição do tipo de investigação que Wolff tomará como sendo aquela que ele deve levar a cabo e, portanto, como sendo aquela reconhecida como propriamente lógica. Apenas para marcar o que poderíamos chamar de influência empirista em sentido lato, acreditamos que cabe ainda uma última observação. No Prefácio à Primeira Edição da Lógica Alemã, Wolff afirma: "Mas, não se pode conhecer os poderes do entendimento humano senão através da experiência à medida que fazemos uso deles." (WOLFF, 1744, a2). Se só conhecemos os poderes do entendimento humano através da experiência, é patente o quanto Wolff deve aos empiristas e, desse modo, podemos concordar com Matt Hettche quando este afirma que descrever Wolff simplesmente como um discípulo de Leibniz ${ }^{4}$ pode ser demasiado enganador (HETTCHE, 2016).

Até aqui nos ocupamos em delinear uma suposta herança lockeana na Lógica Alemã de Christian Wolff. No que se segue, contudo, será importante notar uma descontinuidade no que tange a alguns comprometimentos de Locke, em especial, na compreensão do papel do silogismo e na compreensão da amplitude da lógica.

\section{Christian Wolff e o Método da lógica}

Quando Wolff completa sua dissertação para a obtenção do título de Privatdozent em Leipzig, no ano de 1703, seu trabalho é enviado por Johannes Menke a Leibniz. Esse fato seria desinteressante se não marcasse o início da correspondência entre os dois filósofos, a qual durará até o ano da morte de Leibniz em 1716 (HETTCHE, 2016). Desse acaso biográfico, o que nos interessa é notar que a obra que despertara o interesse de Leibniz versava sobre o uso do método matemático em 
filosofia prática ${ }^{5}$; a importância do método matemático e sua identificação com o método filosófico servirá de pista de leitura para a consideração da natureza da lógica numa segunda fase (ou em uma compreensão mais refinada) da filosofia wolffiana. Isso porque, nos parece, será o apelo justamente ao método matemático o que ficará registrado, na lógica de Wolff, como uma das marcas da influência de Leibniz.

Voltemos, portanto, à compreensão dessa disciplina. Sabemos que na Lógica Alemã, datada originalmente de 1712, Wolff aparece em continuidade com o caminho das ideias no sentido específico em que toma a disciplina da lógica como sendo uma investigação das faculdades cognitivas. Além disso, certamente corresponde ao seu pensamento a compreensão da lógica como um guia na busca da verdade. Essas são as duas características tributárias à influência da lógica das ideias, visto que é nesse sentido, e apenas nesse sentido, que a lógica pode ser concebida como uma arte de pensar. Se olharmos agora para como a lógica é caracterizada no §61 do Discursus praeliminaris de sua Lógica Latina (WOLFF, 1735), encontraremos uma outra característica representativa da compreensão wolffiana, esta, todavia, aparentemente, em descontinuidade com a linhagem lockeana:

$\S 61$ - Definição da lógica. A parte da filosofia, que se ocupa do uso da capacidade de conhecer no conhecimento da verdade e na prevenção do erro, é chamada lógica; ela é, portanto, definida como a ciência da direção da capacidade de conhecer no conhecimento da verdade. (WOLFF, 2006, p. 40, tradução própria)

A definição de lógica que encontramos aqui é ligeiramente diferente daquela da Lógica Alemã, visto que, de acordo com essa última citação, a lógica é uma ciência na direção do conhecimento da verdade. Essa mudança aparentemente superficial representa, contudo, uma profunda diferença entre Wolff e seus antecessores. Para além do preciosismo terminológico, não parece desprezível notar ser essa caracterização mais acurada para o uso destinado por Wolff a essa doutrina ${ }^{6}$ :

§88. Quando se está decidido a buscar o êxito na filosofia, deve-se tratar da lógica em primeiro lugar. Pois a lógica ensina as regras, através das quais a capacidade de conhecer é conduzida ao conhecimento da verdade (§61). (WOLFF, 2006, p. 51, tradução própria)

Apenas uma ciência pode, ao ensinar as regras, conduzir ao conhecimento. Mas, qual seria o estatuto dessas regras? E, além disso, quais seriam essas regras? Comecemos com a primeira questão. Na continuação da citação acima destacada, Wolff escreve:

§89. Os princípios da lógica. Se portanto na lógica tudo deve ser demonstrado, deve-se extrair os princípios da ontologia e da psicologia. Pois, a lógica ensina as regras, através das quais o entendimento é conduzido no conhecimento de todo ente (§61), e sua definição não limita isso a uma arte determinada de ente. Por isso, ela deve ensinar, o que é isso que devemos atentar no conhecimento das coisas. Isso é, no entanto, deduzido [abzuleiten] do conhecimento geral [allgemeinen] do ente, o que é extraído [schöpfen] da ontologia (§73). [...] Além disso, porque a lógica apresenta a arte e o modo na condução do entendimento para o conhecimento da verdade (§61), ela deve explicar o uso de suas operações [isto é, do entendimento] no conhecimento da verdade. O que, entretanto, é a capacidade de conhecer e quais são suas operações, cabe à psicologia ensinar (§58). (WOLFF, 2006, p. 52, tradução própria)

Como resposta à primeira questão levantada, Wolff engendra dois raciocínios. 
Em primeiro lugar, como a lógica ensina as regras para a condução do entendimento no conhecimento de todo e qualquer ente, seus princípios devem ser extraídos do conhecimento geral do ente. Ora, o conhecimento geral do ente é a ontologia. Logo, os princípios da lógica devem ser extraídos da ontologia ${ }^{7}$. Em segundo lugar, como a lógica deve conduzir o entendimento no conhecimento da verdade, ela deve explicar o uso do entendimento - o que é essa capacidade e quais são suas operações. Por sua vez, a investigação que se ocupa das operações do entendimento é, para Wolff, a psicologia. Logo, os princípios da lógica devem ser extraídos igualmente da psicologia.

Contudo, mesmo que os princípios da lógica repousem, em última instância, naqueles da ontologia e da psicologia, na ordem do conhecimento e, portanto, na ordem do estudo das disciplinas filosóficas, é a lógica que deve preceder todas as outras. No $\S 91$ do Discursus Praeliminaris, o autor explica por que a lógica deve vir em primeiro lugar: na ordem do conhecimento [die Methode des Studierens], o aprendizado em psicologia e ontologia não é possível de ser realizado suficiente ou adequadamente sem um conhecimento em lógica, contudo, o contrário pode ser realizado, visto que é possível esclarecer os princípios da ontologia e da psicologia através da lógica. De fato, para Wolff, na ordem do conhecimento, a lógica deve preceder todo e qualquer estudo em filosofia ${ }^{8}$. Isso é possível, como Wolff pretende ter mostrado, porque o método da lógica perpassa o método filosófico.

Dito isso, podemos nos ocupar da resposta à segunda questão levantada, a saber, quais seriam essas regras lógicas. No Capítulo IV do Discursus, Wolff trata do método filosófico e ali sustenta que a filosofia é uma ciência na qual toda afirmação deve ser esclarecida através de uma definição acurada ${ }^{9}$. Além disso, no parágrafo dedicado à forma das proposições [Lehrsätzen] filosóficas $(\S 121)$, Wolff sustentará que na filosofia "deve ser dada a razão por que o possível pode chegar à realidade", o que só pode ser alcançado mediante uma demonstração de "por que algo de alguma coisa deve ser afirmado ou negado" (WOLFF, 2006, p. 71) ${ }^{10}$. Segundo Wolff, essa demonstração é possível quando essa razão repousa "ou na definição ou em alguma condição" (WOLFF, 2006, p. 71). Em ambos os casos, a razão pode ser explicitada via um procedimento racional de prova, isto é, uma espécie de demonstração que exiba a conexão do predicado com o sujeito através de uma razão.

$\mathrm{O}$ método da filosofia segundo o qual um procedimento racional de prova estabelece a conexão entre predicado e sujeito é, para Wolff, o mesmo método matemático, como deixa claro a longa passagem abaixo:

§139. Identidade do método filosófico e do método matemático. As regras do método filosófico são as mesmas do método matemático. Pois no método filosófico não devem ser utilizados senão termos cuidadosamente explicados por uma definição precisa (§116), nem é aceito como verdadeiro senão o que é suficientemente demonstrado $(\S \S 117,118)$; nas proposições, sujeito e predicados são igualmente determinados com cuidado $(\S \S 121,130)$, e tudo é ordenado de tal modo, a fim de que seja antecipado aquilo mediante o qual a sequência é compreendida e provada $(\S \S 133,123,124)$. Mas, por conta de nosso comentário sobre o método matemático [...], torna-se claro que, também no ensino da matemática, os termos devem ser explicados através de uma definição cuidadosa ( $\S \S 17,18$ de Meth.), e que os termos que constituem as definições subsequentes, devem ser explicados nas antecedentes; [...] que os princípios devem ser suficientemente estabelecidos; que, por meio de definições e proposições anteriormente obtidas, são demonstradas proposições de forma rigorosa $(\S \S 43,45$ 
e seg. Meth.), nas quais sujeito e predicado são determinados com precisão ( $\$ 30$ e seg. Meth.). [...] Quem não vê, que as regras do método matemático são as mesmas daquelas do método filosófico? (WOLFF, Discursus, p. 84-5 apud SALTIÉL, 2012, p. 18)

Assim, o método filosófico é concebido como idêntico ao método matemático, visto que, em ambos os casos, esse método consiste em construir demonstrações rigorosas a partir de termos definidos precisamente. O modo através do qual pode-se constuir essas demonstrações, isto é, "antecipar aquilo mediante o qual a sequência é compreendida e provada" (Idem, ibidem) é, para Wolff, a silogística (SALTIÉL, 2012, p. 19). Isso fica claro na passagem abaixo tirada do Brevis comentatio:

$\S 45$. O procedimento de inferência de conclusões a partir de princípios realmente não é outro, senão aquele já exposto em todos os manuais de lógica, em que o silogismo é tratado. [...].

§46. Na verdade não seria difícil demonstrar que uma demonstração genuína, que produz uma convicção plena, não pode ocorrer, caso não ordenemos nossos pensamentos segundo as regras silogísticas [...].

§47. Certamente não ignoro haver em nosso tempo presente não poucos que estão persuadidos de que a forma das demonstrações matemáticas é diferente das leis dos silogismos, e que concedem ainda menos que todo o poder de convicção daquelas advém unicamente destas. Mas não me é oculto que a homens dotados não apenas de ilustre capacidade de juízo, mas também de atenção rigorosa, veem o contrário. Sua autoridade me impeliu a investigar a questão a fundo e dessa maneira conheci o preconceito que surgiu através de um juízo precipitado" (Wolff, Brevis comentatio, $\S \S 45-47$, pp. 13-14 apud SALTIÉL, 2012, p. 19)

Conclui-se, portanto, que, para Christian Wolff, o método comum da matemática e da filosofia não é outro do que a silogística (SALTIÉL, 2012, p. 22-3) (CAPPOZI; RONCAGLIA, 2009, p. 126). Por esse motivo, Capozzi e Roncaglia podem afirmar que "Depois de Wolff, a lógica é entendida como a única estrutura argumentative usada em todo o campo de conhecimento, da matemática à filosofia." (CAPPOZI; RONCAGLIA, 2009 , p. 129). No entanto, sabe-se que tanto Locke, quanto Thomasius, concebem o silogismo como estéril. Desse modo, para estes últimos pensadores, o silogismo não possui a característica que Peter Geach atribui ao ato de argumentar, a saber, a capacidade de nos levar a adotar crenças com base em razões (GEACH, 2012, p. 17$8)^{11}$. Portanto, a concepção segundo a qual o silogismo é um método legítimo de obter conhecimento não pode ser originária, em Wolff, dessa linhagem de influência. Queremos ler essa compreensão dos poderes da lógica geral (aqui compreendida simplesmente como silogística) como podendo ser tributária à influência leibniziana.

\section{LEIBNIZ E O ELOGIO AO SILOGISMO}

Vejamos brevemente algumas passagens do Livro IV dos Novos Ensaios sobre o Entendimento Humano de Leibniz a fim de traçar algumas características de sua compreensão do papel da lógica, para registrarmos aquilo que estamos compreendendo como uma possível herança deixada em Christian Wolff ${ }^{12}$. Faremos isso olhando, em linhas muito gerais, para o modo como Leibniz trata o silogismo como um método para alcançar a verdade. 
Antes disso, vale dizer que, como, para Leibniz, os signos (ou a linguagem) são necessários para o pensamento, importa saber como esses signos podem ser corretamente combinados a fim de formar proposições que expressam pensamentos e, além disso, que possam expressar - se bem formados - pensamentos verdadeiros. Dessa ideia inicial, surge sua Dissertação sobre a Arte Combinatória, a qual consta como um trabalho de sua juventude onde Leibniz pretende expor um sistema de lógica formal com a sintaxe da linguagem do pensamento. Esse sistema:

Não apenas permitiria ver se uma proposição se segue ou não de outras
proposições; ele permitiria ver como uma proposição que parece simples poderia
ser analisada em conceitos constituintes mais simples ainda, nos quais ambos o
significado e a verdade da proposição estão baseados. (ISHIGURO, 1990, p. 44,
tradução própria)

Desse modo, se os termos simples puderem ser definidos e todas as operações puderem ser expostas, todos os conceitos complexos e, portanto, todas as proposições, poderiam ser obtidos via a aplicação reiterada dessas regras (ISHIGURO, 1990, p. 45). Assim, a vantagem desse instrumento seria poder extrair todo o conhecimento dedutível

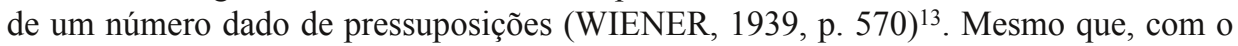
passar dos anos, o próprio Leibniz tenha rejeitado sua arte combinatória como uma pretensão juvenil ${ }^{14}$, não parece ser o caso que ele tenha rejeitado a compreensão de que é na lógica que a questão da verdade (leia-se, de toda verdade) se resolve. Isso pode ser sustentado, assim nos parece, visto que encontramos nos Novos Ensaios: i) uma compreensão da verdade como concordância entre as ideias e, em especial, a tese da inerência do predicado ao sujeito e; ii) uma compreensão da lógica geral, naquilo que nos interessa representada pela silogística, como sendo o método que permite, a exemplo do método matemático, estabelecer essa relação. Vejamos, em primeiro lugar, como a verdade é compreendida na relação entre as ideias:

Tomando-se, porém, o conhecimento num sentido mais estrito, isto é, como conhecimento da verdade, como fazeis aqui, digo ser verdadeiro que a verdade está sempre fundada na concordância ou discordância das ideias, porém não é em geral verdade que o nosso conhecimento da verdade constitui uma percepção desta concordância ou discordância, a não ser que se diga que a sentimos confusamente, sem dar-nos conta. (LEIBNIZ, 1980, p. 286)

Tomar a verdade como estando fundada na concordância ou discordância das ideias significa, para Leibniz, tomar uma proposição como verdadeira se e somente se a noção do predicado está incluída na noção do sujeito: trata-se do conhecido princípio praedicatum inest subject. O peculiar do dictum leibniziano é que essa compreensão intensional das relações entre sujeito e predicado deve ser estendida não apenas às proposições, na linguagem kantiana, ditas analíticas ${ }^{15}$, mas a toda e qualquer proposição ${ }^{16}$. O que fica claro em sua defesa desse princípio na seguinte carta a Arnauld: “em toda proposição afirmativa, seja necessária ou contingente, universal ou particular, a noção do predicado está de algum modo incluída naquela do sujeito. Praedicatum inest subjecto; de outro modo, eu não sei o que a verdade é." (LEIBNIZ apud LOOK, 2014) Nesse contexto, estabelecer a verdade de uma proposição, de qualquer proposição, é compreender a inerência ou não de um predicado a um sujeito, a fim de examinarmos as propriedades essenciais de uma substância ${ }^{17}$. Portanto, se por ventura nos depararmos com uma proposição verdadeira na qual uma 
ideia não nos parece evidentemente inerente a outra, isto é, cujo predicado não nos parece estar evidentemente contido no sujeito, isso ocorre não porque ele de fato não pertence aí, mas porque não o compreendemos devidamente:

Via de regra, quando as ideias são compreendidas a fundo, as suas concordâncias e discordâncias aparecem. Reconheço, porém, que por vezes existem algumas tão compostas, que se necessita de muito cuidado para explicitar o que nelas está escondido; sob este aspecto, certas concordâncias podem permanecer ainda obscuras. (LEIBNIZ, 1980, p. 301)

Resta-nos, portanto, compreender por qual método seríamos capazes de revelar essa conexão profunda. E aqui a lógica tem um papel a cumprir: ora, sendo a verdade a concordância ou discordância entre as ideias, cabe à lógica revelar essas conexões. As passagens abaixo, retiradas do Livro IV dos Novos Ensaios, devem ser úteis para traçar a definição e amplitude dessa disciplina:

Com efeito, a lógica é tão suscetível de demonstrações como a geometria, podendo-se afirmar que a lógica dos geômetras, ou as maneiras de argumentar que Euclides explicou e estabeleceu ao falar das proposições, constitui uma extensão ou promoção particular da lógica geral. (LEIBNIZ, 1980, p. 297)

Começo agora a entender o que é uma ligação das ideias conhecida distintamente, e bem vejo que desta forma os axiomas são necessários. Vejo bem, igualmente, como é necessário que o método que seguimos nas nossas pesquisas quando se trata de examinar as ideias seja regulado conforme os exemplos dos matemáticos, que partindo de certos indícios muito claros e fáceis - que não constituem outra coisa senão os axiomas e as definições - sobem em pequenos degraus e por encadeamento contínuo de raciocínios até à descoberta e à demonstração das verdades que de início parece superar a capacidade humana. (LEIBNIZ, 1980, p. 368)

A lógica é compreendida aqui como uma espécie de cálculo ou demonstração capaz de evidenciar as conexões profundas entre as ideias e, desse modo, possibilitar o acesso ao conhecimento. Além disso, embora Leibniz não tenha tido sucesso em sua empresa de "aritmetizar" a lógica através de sua arte combinatória, persiste em sua compreensão madura da lógica a ideia de que o estabelecimento da verdade é tributário a um método dedutivo. Esse método, por sua vez, encontrará uma de suas expressões justamente na silogística, ou seja, na "arte de encontrar ideias médias": "Após ter estabelecido ideias claras e distintas com nomes fixos, o grande meio de aumentar os nossos conhecimentos é a arte de encontrar ideias médias" (LEIBNIZ, 1980, p. 370).

Segue-se dessa compreensão do papel da silogística um elogio a essa invenção dos antigos:

[...] estou convencido de que a invenção dos silogismos constitui uma das mais belas do espírito humano, e até uma das mais belas do espírito humano, e até uma das mais consideráveis. É uma espécie de matemática universal, cuja importância não é suficientemente conhecida. Pode-se dizer que o silogismo encerra uma arte de infalibilidade, desde que se saiba e se tenha capacidade para bem usá-lo, o que nem sempre acontece. (LEIBNIZ, 1980, p. 391) ${ }^{18}$

Os Novos Ensaios estão estruturados na forma de simular uma conversa entre dois amigos imaginários: Filaleto e Teófilo. Filaleto teria retornado de uma viagem à Inglaterra bastante impressionado pela leitura do Ensaio sobre o entendimento humano 
de John Locke e representaria, no diálogo, as ideias deste último. Teófilo, por outro lado, representaria o pensamento de Leibniz. No Livro IV, cap. XVII ( $A$ razão), os dois amigos travam uma discussão acerca de dois pontos concernentes à importância da silogística. Em primeiro lugar, cabe compreender de onde deriva a força da silogística e por que ela pode garantir a corretude dos raciocínios, em segundo lugar, trata-se de investigar sua proficuidade. Teófilo tentará mostrar que o ceticismo de Filaleto acerca da infecundidade do silogismo deriva de sua incompreensão com respeito ao enraizamento dessa maneira de raciocinar nas formas universais da lógica. Comecemos observando a incredulidade de Filaleto no que concerne ao primeiro ponto:

Acredita-se geralmente que o silogismo é o grande instrumento da razão e o melhor meio para pôr esta faculdade em exercício. Quanto a mim, tenho dúvidas, pois o silogismo serve apenas para ver a conexão das provas num só exemplo e não vai além disso, ao passo que o espírito vê esta conexão facilmente, e talvez melhor sem o silogismo. Os que sabem utilizar as figuras e os modos supõem o mais das vezes o seu uso e utilidade em virtude de uma fé implícita nos seus mestres, sem saber a razão. [...] Trata-se de saber que conexão tem uma ideia média com os extremos no silogismo: ora, é isto que nenhum silogismo é capaz de mostrar. É o espírito que pode perceber tais ideias colocadas assim por uma espécie de justaposição, e isto pela sua própria vista. Para que serve então o silogismo? Ele tem utilidade nas escolas, onde não se tem vergonha de negar a concordância das ideias que visivelmente concordam. (LEIBNIZ, 1980, p. 38990)

A reação de Teófilo é imediata (para evitar citação repetida, omitimos o trecho, já citado acima, no qual Teófilo elogia o silogismo):

Cumpre reconhecer que a forma escolástica dos silogismos é pouco usada no mundo; além disso, que ela é excessivamente longa e complicada, se quiséssemos empregá-la com seriedade. [...]

Entretanto, é necessário saber que, ao falar dos argumentos em forma, não entendo exclusivamente esta maneira escolástica de raciocinar que se utiliza nos colégios, mas todo raciocínio que conclui pela força da forma, e onde não há necessidade de suprir ponto algum, de maneira que um sorites, um outro tipo de silogismo que evite a repetição, um cálculo de álgebra, uma análise dos infinitesimais serão para mim mais ou menos argumentos em forma, porque a sua forma de raciocinar foi pré-demonstrada, de maneira que estamos seguros de não nos enganar. [...] Essas inversões, composições e divisões das razões, das quais se serve Euclides, não passam de espécies de formas de argumentar particulares e próprias aos matemáticos e à matéria com a qual se ocupam, e demonstram essas formas com o auxílio das formas universais da lógica. (LEIBNIZ, 1980, p. 391)

A longa citação acima deve servir para compreender o que Leibniz entende especificamente pela silogística e, em decorrência disso, por que essa arte de argumentar é profícua no estabelecimento do conhecimento. Para Leibniz, o silogismo deriva sua força e, como ele, toda e qualquer maneira correta de raciocinar, da sua forma. Trata-se, portanto, de atentar para a forma dos raciocínios - quaisquer que eles sejam - em relação com as formas universais da lógica para verificar sua capacidade de produzir as corretas consequências. Assim, a lógica seria a forma universal subjacente a toda e qualquer maneira de raciocínio, isto é, a regra de sua corretude ${ }^{19}$. Assim, ao menosprezar a capacidade do silogismo em garantir a corretude nos raciocínios, Filaleto não compreende que o silogismo, apenas uma entre outras maneiras de raciocinar, 
porque está fundado na lógica, pode conduzir ao conhecimento e, portanto, consiste em uma maneira fecunda de raciocinar: "Englobando sob os silogismos também os conjuntos de silogismos e tudo aquilo que denominei argumentação em forma, pode-se dizer que o conhecimento que não é evidente por si mesmo se adquire através de consequências, as quais só são corretas quando possuem a força devida." (LEIBNIZ, 1980, p. 395)

E assim, Filaleto, enfim, sucumbe à argumentação de Teófilo:

Começo a fazer da lógica uma ideia completamente diversa da que possuía outrora. Considerava-a como uma brincadeira de escolares, ao passo que agora vejo que existe uma espécie de matemática universal, da forma como entendeis. Oxalá se conseguisse fazê-la progredir mais do que até agora, a fim de que possamos encontrar nela esses verdadeiros subsídios ou meios da razão, dos quais falava Hooker, meios que elevariam os homens bem acima do seu estado atual. (LEIBNIZ, 1980, p. 397-8)

Conclusão

Como vimos, o quadro afigura-se complexo. Por um lado, como pretendemos ter mostrado, é enganador descrever Christian Wolff apenas como um seguidor de Leibniz, visto que, segundo alguns pontos importantes de sua filosofia, Wolff está em continuidade com certos aspectos da rejeição à filosofia escolástica trazida pelo Ensaio de John Locke. Para relembrar, esses pontos são, os seguintes: i) há um elogio aos poderes do entendimento humano; ii) segue-se disso, a necessidade de se investigar esses poderes - a lógica é o resultado de uma investigação sobre o entendimento; iii) sem a experiência não é possível o conhecimento dos poderes do entendimento (isso aparece notoriamente no papel fundamental reservado à psicologia para o estabelecimento das verdades lógicas).

Por outro lado, Christian Wolff parece não estar disposto a renunciar de todo à tradição escolar que recebera. Isso porque, ele também aparece como herdando de Leibniz e/ou da tradição duas ideias fundamentais para sua própria concepção de lógica. Em primeiro lugar, observa-se uma valorização do método matemático como idêntico ao método filosófico à medida que ambos estão fundados na lógica; testemunho disso é o fato de que a lógica passa a ser vista como $a$ estrutura subjacente à toda a forma de pensamento. Em segundo lugar, o reconhecimento de que a silogística não é apenas um método legítimo de conhecimento, mas que esse procedimento (e com ele assunções decorrentes da lógica) poderiam levar à extensão do conhecimento. Se, para Christian Wolff, a lógica não é, como parece ser para Leibniz, o organon de toda a verdade, ela não pode tampouco ser reduzida a um mero cânone da verdade, visto que, ao menos no que concerne ao silogismo, parece haver o consenso de que ele é um método legítimo de obter conhecimento. A lógica tem, portanto, uma aplicação prática a ser explorada: ela pode levar ao conhecimento. O resultado do encontro dessas duas tradições na lógica de Wolff é uma compreensão de um duplo método nessa disciplina, pois, para que essa ciência nos guie na busca da verdade, ela própria buscaria seus princípios na psicologia e na ontologia.

\section{REFERÊNCIAS}

CAPPOZI, M.; RONCAGLIA, G. Logic and Philosophy of Logic from Humanism to Kant. In: HAAPARANTA, L. (Ed.). The Development of Modern Logic. New 
York: Oxford University Press, 2009.

COUTURAT, L. La Logique de Leibniz d'après des Documents Inédits. Paris: Felix Alcan, 1901.

GEACH, P. Argumentar e dar razões. Porto Alegre: Penso, 2012.

HETTCHE, M. "Christian Wolff". In: The Stanford Encyclopedia of Philosophy (Winter 2014 Edition). E. ZALTA (ed.). Disponível online em: $<$ http://plato.stanford.edu/archives/win2014/entries/wolff-christian/>.

ISHIGURO, H. Leibniz's Philosophy of Logic and Language. New York: Cambridge University Press, 1990.

KANT, I. Lógica. Tradução do texto original estabelecido por Gottlob Jäsche de Guido Antônio de Almeida. 3a. Edição. Rio de Janeiro: Tempo Brasileiro, 2003.

KNEALE, W.; KNEALE, M. O desenvolvimento da lógica. Lisboa: Fundação Calouste Gulbenkian, 1980.

LEIBNIZ, G. W. Novos Ensaios sobre o Entendimento Humano. Trad. Luiz João Baraúna. Coleção Os ed. São Paulo: Abril Cultural, 1980.

LOCKE, J. An Essay concerning Human Understanding - Collated and Annotated, with Prolegomena, Biographical, Critical, and Historical by Alexander Campbell Fraser. Oxford: Clarendon Press, 1894.

LOOK, B. C. "Gottfried Wilhelm Leibniz". In: The Stanford Encyclopedia of Philosophy (Spring 2014 Edition), E. ZALTA (ed.). Disponível online em: $<$ http://plato.stanford.edu/archives/spr2014/entries/leibniz/>.

MACFARLANE, J. "Frege, Kant, and the Logic in Logicism". In: The Philosophical Review, v. 111, n. 1, 2002.

SALTIÉL, E. R. VON. Wolff e o jovem Kant: os princípios de contradição e de razão e a prova da existência de Deus. Dissertação de Mestrado. Universidade Federal do Rio Grande do Sul, Porto Alegre, 2012.

SEIXAS DA SILVA, M. Lógica e formação de conceitos em Kant. Tese de Doutorado. Universidade Federal do Rio Grande do Sul, Porto Alegre, 2016.

WIENER, P. P. "Notes on Leibniz' Conception of Logic and its Historical Context". In: The Philosophical Review, v. 48, n. 6, p. 567-586, 1939.

WOLFF, C. Philosophia Rationalis sive Logica [Lógica Latina]. Verona: Ex Typographia Dionysi Ramanzini, 1735.

WOLFF, C. Vernünfftige gedancken von den kräfften des Menschlichen verstandes und ihrem richtigen Gebrauch in erkantniss der Wahrheit [Lógica Alemã]. Halle: Halle im Magdeb, 1736. Disponível integralmente em: https://archive.org/stream/bub_gb_MY8_AAAAYAAJ\#page/n33/mode/2up

WOLFF, C. La logique ou Refléxions sür les forces de l'entendement humanin, et sur leur légitime usage dans la connaissance de la verité [Lógica Alemã, tradução francesa autorizada por Wolff]. Lausanne \& Genève: Marc-Mich. Bousquet \& Comp., 1744. Disponível integralmente em: https://archive.org/stream/lalogiqueourefle00wolf\#page/n19/mode/2up.

WOLFF, C. Philosophia Rationalis sive Logica [Lógica Latina, tradução alemã]. Stuttgart-Bad Cannstatt: Friedrich Frommann Verlag, 2006.

\section{NoTAS}

1 “A Lógica ou arte de pensar (1662), mais conhecida como Lógica de Port-Royal, ocupou de muitas maneiras uma posição intermediária entre Locke e seus predecessors aristotélicos." (SCHUURMAN, 2000, p. 69, em inglês no original)

2 Poderia ser frutífero comparar o início do Primeiro Prefácio da Lógica Alemã de Wolff com o texto $O$ que é o iluminismo de Kant, visto que, não apenas o entusiasmo aparece nos dois textos, mas também a crítica àqueles que não se valem da sua condição racional. Esse trabalho, contudo, não será realizado aqui.

3 No original : "Was ich nun bey Durchlegung matematischer Schrifften und bey vielfältigem 
eigenem Nachsinnen von dem Gebrauche der Kräffte des menschlichen Verstandes angemercket; davon habe das leichteste und was am ersten zu wissen nötig ist, in kurze Regeln verfassen wollen.“(WOLFF, 1736)

$4 \mathrm{Ou}$ ainda descrever Christian Wolff simplesmente como um neo-leibniziano pode igualmente ser injusto (MACFARLANE, 2002, p. 4).

5 Sobre o início da correspondência com Leibniz, o próprio Wolff escreve: "Em 1703 eu escrevi um tratado sobre filosofia prática universal, usando o método matemático. Eu submeti esse trabalho ao exame de homens versados no debate público na Academia de Leipzig, pois seu estatuto requer que um trabalho acadêmico seja apresentado por qualquer um que queira se tornar um doutor. Por esse trabalho, eu fiquei conhecido de Leibniz, que, depois de obter uma cópia dele por Johannes Mencke, julgou que eu era digno de sua graça e amizade. Eu escrevi esse trabalho quando eu era muito jovem, imitando alguns dos matemáticos recentes que deram um tratamento geral dos princípios da aritmética e da geometria na matemática universal comum. Neste trabalho, quando eu ainda descubro um sólido conteúdo, mesmo depois de ter meditado e ter escrutinado suas razões mais profundamente [...]". (WOLFF, Discurso Preliminar, 1728 apud HETTCHE, 2016). A Lógica Latina pode ser igualmente consultada em uma edição de 1735 no Internet Archive, ver referências bibliográficas.

6 Para que faça algum sentido fazer essa distinção, ignorando o modo como o próprio filósofo nomeia, por vezes, sua doutrina, é preciso dizer que essa compreensão da lógica como ciência é o que corresponde melhor ao "espírito" da lógica de Wolff - mesmo que para o autor a diferença terminológica não seja tão importante. Ver, por exemplo: Discursus Praeliminaris, $\S 89$ (WOLFF, 2006, p. 52).

7 Macfarlane nota que a generalidade da lógica assumida por Wolff, quando ele diz que "a lógica ensina as regras, através das quais o entendimento é conduzido no conhecimento de todo ente", não implica seu comprometimento com a formalidade, isto é, com a característica de que a lógica deve abstrair inteiramente do conteúdo do conhecimento (MACFARLANE, 2002, p. 45). Como fica claro na citação acima, a lógica não abstrai de todo o conteúdo, ela leva em conta princípios, nas palavras de MacFarlane, de alta generalidade, como aqueles contidos na ontologia. Além disso, é necessário notar, algo deixado de lado por MacFarlane, para Wolff, não são apenas os princípios da ontologia que alimentam a lógica, mas igualmente, como fica claro na citação do $\S 89$, os princípios da psicologia. Segundo o autor, e essa é uma pista para uma investigação futura, essa é a visão da lógica contra a qual Kant irá reagir em seus próprios escritos a esse respeito.

8 Conferir a seguinte passagem: "\$91. Por que o autor trata a lógica em primeiro lugar. $\mathrm{O}$ método demonstrativo exige que a lógica seja ensinada depois da ontologia e da psicologia (90), o método de estudo sugere todavia que ela seja anteposta a todas as partes restantes da filosofia e, portanto, preceda também a ontologia e a psicologia (88). Ambos métodos não podem conjuntamente ser satisfeitos. Depois de uma observação cuidadosa do assunto, nós compreendemos que, porque quem não teve ainda nenhum contato com a lógica não pode suficientemente aprender [tun kann] ontologia e psicologia, mas que os princípios da ontologia e da psicologia, que a lógica precisa, podem muito facilmente ser esclarecidos na própria lógica, preferimos o método do estudo ao invés do método da demonstração.” (WOLFF, 2006, p. 53) Estamos aqui tomando como sinônimas, as expressões "método de estudo" e "ordem do conhecimento", bem como "método da demonstração" e "ordem das razões".

9 Conferir, especialmente: "§116. In der Philosophie dürfen keine Ausdrücke verwendet werden, die nicht durch genaue Definition erklärt sind." (WOLFF, 2006, p. 67)

10 Para conferir a passagem completa: "Nas proposições [Lehrsätzen] filosóficas deve-se determinar a condição adequadamente, sob a qual o predicado pertence ao sujeito ou sob a qual algo de alguma coisa é afirmado ou negado. Na filosofia deve ser dada a razão por que o possível pode chegar à realidade (31), portanto, por que algo de alguma coisa deve ser afirmado ou negado. Se então a razão, por que um predicado pertence a um sujeito, está contida ou na definição ou em alguma condição, o filósofo deve mostrar como em virtude dessa definição ou em virtude dessa condição o predicado pertence ao sujeito. Por 
conseguinte, ele deve escrever a demonstração, que exibe claramente, se o predicado pertence ao sujeito em virtude da definição ou em virtude de alguma condição, e a condição deve ser adequadamente determinada; a não ser que ela se siga per se em virtude da definição. A mesma demonstração pode ser comprovada de outro modo. Quando a condição sob a qual o predicado pertence ao sujeito na demonstração não é adequadamente demonstrada, permanece questionável, se o predicado pertence ao sujeito completamente, isto é, em todo caso, ou se apenas sob uma certa condição, isto é, em algum caso determinado; muito menos se reconhece em qual caso ele deve ser atribuído. Quem está com dúvidas nessa ignorância, não alcançou conhecimento seguro [...]" (WOLFF, 2006, p. 71).

11 Se utilizarmos a distinção de Peter Geach entre os atos de dar razões (argumentar) e racionalizar, talvez pudéssemos dizer que, para Locke e Thomasius os silogismos seriam meras racionalizações e não argumentações capazes de nos levar à adoção de crenças com base em razões.

12 É necessário uma nota acerca da possível descontinuidade histórica da linha de influência que estamos tentando marcar. Os Novos Ensaios de Leibniz são publicados apenas tardiamente em 1765, o que, por si só, coloca em dúvida qualquer possível influência direta desse trabalho sobre a filosofia de Christian Wolff ou mesmo sobre sua influência em qualquer de seus contemporâneos. Sabe-se, contudo, que Leibniz redige os Novos Ensaios entre 1701 e 1704 e, portanto, exatamente quando se inicia a correspondência com Christian Wolff, o que pode ter contribuído para um intercâmbio de suas ideias (CAPPOZI; RONCAGLIA, 2009, p. 122). É claro que apenas uma minuciosa e criteriosa análise dessa correspondência pode dar conta de uma resposta completa a nossa hipótese de leitura. No entanto, fazer isso excede em muito nossos objetivos.

13 Isto é, deveria ser possível reduzir toda a multiplicidade conceitual a conceitos simples de modo que cada termo complexo seria o resultado de uma combinação de seus constituintes mais simples. Conforme Capozzi e Roncaglia: "O segundo resultado da Arte Combinatória que vale ser mecionado é a construção de uma linguagem simbólica na qual os números sao usados para representar conceitos simples ou primitivos, e suas combinações (subdivididas em classes de acordo com o números dos conceitos primitivos que estão envolvidos) são usadas para representar conceitos complexos ou derivados". (2009, p. 110, tradução própria)

14 Sobre a rejeição de Leibniz a essa obra: "Foi o que ocorreu com a minha obra Arte das Combinações, fato que já tive ocasião de lamentar. Foi um fruto da minha primeira adolescência, e, todavia, a obra foi reimpressa por muito tempo, sem consultar-me e mesmo sem observar que se tratava de uma segunda edição. Isso levou alguns a crerem, a meu desfavor, que eu era capaz de publicar uma tal obra em idade avançada. Com efeito, embora existam ali teses que ainda aprovo, outras há que só podem convir a um jovem estudante." (LEIBNIZ, 1980, p. 309)

15 Para uma compreensão diferente do princípio praedicatum inest subject: "Couturat argumentou que para Leibniz todas as verdades dependem do termo predicado estar contido no termo sujeito, todas verdades seriam, para ele, analíticas. Eu espero mostrar, contudo, que ambas as questões, a da forma sujeito-predicado das proposições e o problema da 'analiticidade' das verdades, são muito mais complexas do que Couturat compreende. ('Analiticidade' não era um conceito que Leibniz usava com o significado pós-kantiano que nós atribuímos a ele.) Couturat também indicou, corretamente, a importância da tentativa de Leibniz, que durou sua vida inteira, de construir um Sistema de lógica formal que, por conta de sua sintaxe corresponder às leis do pensamento, forneceria um procedimento para determinar o valor de verdade de todo pensamento humano expresso por ele." (ISHIGURO, 1990, p. 10, tradução própria)

16 Ver, por exemplo: "Há na verdade uma distinção entre verdades de razão, que são verdadeiras em todos os mundos possíveis e verdade de fato que em certo sentido são contingentes porque dependem da vontade de Deus e só são verdadeiras no mundo atual. Mas o princípio da razão suficiente assegura-nos que mesmo as verdades de fato são necessárias na medida em que nada acontece sem um motivo. Em toda a proposição verdadeira o 
conceito expresso no sujeito contém o conceito do predicado e a diferença entre verdades de razão e verdades de fato é simplesmente que as últimas não podem ser demonstradas sem referência a essa superioridade do mundo atual que levou Deus a escolhê-lo entre todos os mundos possíveis." (KNEALE; KNEALE, 1980, p. 340)

17 Conferir, por exemplo: "Demonstrar uma proposição é mostrar que o conceito do seu predicado está contido no conceito do sujeito e para isso temos que analisar os dois conceitos com suficiente amplitude para esclarecer melhor as relações entre ambos." (KNEALE; KNEALE, 1980, p. 337-8)

18 Também citado por Louis Couturat (COUTURAT, 1901).

19 Como observa Philip Paul Wiener, para Leibniz a lógica era importante não apenas por razões de rigor, mas também para razões práticas, isto é, para o conhecimento em campos tão diversos quanto a física, a matemática e o direito (WIENER, 1939, p. 568-70). 